\title{
Clinical and Economic Burden of Commercially Insured Patients with Acromegaly in the United States: A Retrospective Analysis
}

\author{
Hilary Placzek, PhD, MPH; Yaping Xu, MD, MPH; Yunming Mu, PhD; Susan M. Begelman, MD; \\ and Maxine Fisher, PhD
}

\begin{abstract}
BACKGROUND: Acromegaly is a chronic disorder characterized by excess growth hormone secretion and elevated insulin-like growth factor-1 levels most often caused by a pituitary adenoma. Clinical presentation of the disease includes coarsening of the facial features, soft-tissue swelling of the hands and feet, and overgrowth of the frontal skull and protrusion of the jaw, as well as joint symptoms. Acromegaly is associated with several comorbidities, including diabetes, cardiovascular disease, and arthropathy, which, if left untreated, can lead to early mortality. Surgery to remove the adenoma is the first-line treatment for many patients, but more than $50 \%$ of patients will require additional pharmacologic or radiation therapy.
\end{abstract}

OBJECTIVES: To (a) determine the clinical and economic burden of illness among patients with acromegaly using administrative claims data from a large, commercially insured population in the United States and (b) estimate the most frequent acromegaly-related comorbidities and health care resource utilization and costs among these patients.

METHODS: This retrospective, observational cohort study used administrative claims data from the HealthCore Integrated Research Database, containing a geographically diverse spectrum of longitudinal claims data from the largest database of commercially insured patients in the United States. Patients were aged $\geq 20$ years and fulfilled $\geq 1$ of the following criteria during the intake period (March 31, 2008-July 31, 2012): $\geq 2$ independent diagnostic codes for acromegaly, $\geq 1$ acromegaly diagnosis code and $\geq 1$ acromegaly-related procedure code, or $\geq 1$ acromegaly diagnosis code and $\geq 1$ medical claim for acromegaly-related therapy. The index date was defined as the date of the first medical claim for acromegaly within the intake period. Assessed outcomes included prevalence of acromegaly diagnosis and incidence of new acromegaly diagnoses during the study period (January 1, 2008-July 31, 2013), acromegaly-related comorbidities, and pharmacotherapy use. Because 2008 and 2012 data were incomplete, incidence rates were only reported for 2009,2010 , and 2011. Total and acromegaly-related health care resource utilization and annual health care costs were analyzed during a 12-month post-index observational period.

RESULTS: In total, 757 patients with acromegaly met the selection criteria for this study, with a mean age of 49.3 years ( $53.6 \%$ female). The total prevalence of acromegaly was 41.7 cases per million. Acromegaly incidence was 15.0,13.3, and 9.5 cases per million in 2009, 2010, and 2011, respectively. The top 5 acromegaly-related comorbidities were hypertension, diabetes, hypothyroidism, arthropathy/arthralgia/synovitis, and sleep apnea. During the study period, $51 \%$ of patients $(n=385)$ used acromegaly-related pharmacologic therapy, with the most common being cabergoline and octreotide (used by $12.4 \%$ and $12.2 \%$ of patients, respectively). Overall, $18.8 \%$ of patients incurred an acromegaly-related inpatient stay; $97.0 \%$ used outpatient services other than emergency room (ER) or physician visits; $74.8 \%$ had a physician office visit; and $1.8 \%$ visited the ER for acromegaly-related reasons. In the 12-month post-index period, $37.0 \%$ of patients filed claims for acromegaly-related prescription drugs, and patients with $>1$ claim had an average of 7.6 prescriptions. The most expensive acromegaly-related costs in this study population were inpatient hospitalizations $(\$ 6,754)$ and prescription drugs $(\$ 6,147)$.

CONCLUSIONS: Consistent with previous studies, this study confirms that acromegaly is a rare condition associated with multiple comorbidities. Notably, $18.8 \%$ of this study population required an inpatient hospital admission during the 12-month post-index period, possibly because of severe comorbidities. Because acromegaly-related costs were driven by hospitalizations and pharmacotherapy, improved management of the disease may reduce the clinical and economic burden experienced by patients with acromegaly.

J Manag Care Spec Pharm. 2015;21(12):1106-14

Copyright $\odot 2015$, Academy of Managed Care Pharmacy. All rights reserved.

\section{What is already known about this subject}

- Acromegaly is a rare, chronic disorder characterized by excess growth hormone secretion and elevated insulin-like growth factor-1 levels, often caused by a pituitary adenoma.

Acromegaly is associated with significant comorbidities, which, if left untreated, can increase mortality.

Many acromegaly patients are not cured by surgery and will require lifelong pharmacologic therapy. In addition, for patients in surgical remission, the disease may still require lifelong treatment for various comorbidities, such as permanent joint disease, as well as symptomatic relief.

\section{What this study adds}

Evidence from a large, comprehensive database of commercially insured U.S. patients indicates that more than half of patients with acromegaly use acromegaly-related pharmacologic therapy. These data draw attention to the economic burden imposed by acromegaly, with related health care costs primarily driven by inpatient admissions and prescription drugs.

\footnotetext{
1 cromegaly is a chronic disorder of excess growth $\triangle$ hormone $(\mathrm{GH})$ secretion and elevated insulin-like 1 growth factor-1 (IGF-1) levels, most often caused by a GH-secreting pituitary adenoma. ${ }^{1,2}$ Clinical presentation of the disease includes coarsening of the facial features, softtissue swelling of the hands and feet, overgrowth of the frontal skull and protrusion of the jaw, and joint symptoms arising from cartilaginous proliferation. ${ }^{2-5}$ Significant comorbidities of
} 
acromegaly include diabetes, cardiovascular disease, arthropathy, hypopituitarism, sleep apnea, and colon polyps. ${ }^{6-9}$ If the disease is left untreated, patients are at an increased risk of mortality. ${ }^{10}$

Acromegaly is a rare disease that affects men and women equally. ${ }^{11}$ Although acromegaly prevalence (based on acromegaly diagnosis) has been estimated at 40-70 cases per million people, ${ }^{12-19}$ the true prevalence may be higher because of underdiagnosis. ${ }^{11}$ Proactive screening for the disease in primary health care centers by measurement of IGF-1 levels or assessment of characteristic symptoms (via a questionnaire) has yielded considerably higher estimated disease rates ( $>290$ cases per million). ${ }^{20,21}$ When diagnosis of acromegaly is made, it is upon presentation of clear differentiating symptoms, most often in patients between the ages of 40 and 50 years. ${ }^{10,11,15,22}$

Treatment for acromegaly is focused on reducing or stabilizing tumor size, controlling GH activity, reducing symptoms, and preventing associated comorbidities and early mortality. ${ }^{5}$ For most patients, surgical resection of the pituitary adenoma is the recommended primary treatment and may lead to normalization of GH and IGF-1 levels, depending on characteristics of the adenoma and biochemical activity. However, for patients who do not achieve postoperative GH or IGF-1 normalization or for whom surgery is not possible, lifelong pharmacologic therapy is necessary. Somatostatin analogs (octreotide, lanreotide, or pasireotide) or the GH receptor antagonist pegvisomant are recommended for patients with significant disease, while dopamine agonists (cabergoline or bromocriptine) are recommended for patients with milder disease. Use of combination pharmacotherapy and/or addition of radiotherapy or stereotactic radiotherapy may also be necessary to achieve disease control.

Treatment of acromegaly and its associated comorbidities contribute to the substantial economic burden associated with the disease..$^{9,23-28}$ However, studies examining the economic burden of acromegaly in the United States are limited. The objectives of this study were to investigate the clinical and economic burden of illness among patients with acromegaly using administrative claims data from a large commercially insured population in the United States and to evaluate disease-related comorbidities and estimate health care resource utilization and costs among these patients.

\section{Methods}

\section{Study Design and Patient Selection}

This retrospective, observational cohort study used administrative claims data from the HealthCore Integrated Research Database (HIRD). The HIRD contains a broad, clinically rich, and geographically diverse spectrum of longitudinal claims data from WellPoint health plans in the Northeast, South, Midwest, and West regions of the United States. It includes data from preferred provider organizations (PPOs), health maintenance organizations (HMOs), point-of-service (POS) plans, consumer-directed health plans, and indemnity plans and represents the largest database of commercially insured patients in the United States. At the time of this study, patient records were available from January 1, 2006, to July 31, 2013.

Patients included in this study were identified from a review of available HIRD claims data during the intake period, defined as March 31, 2008-July 31, 2012. Index date was defined as the date of the first medical claim for acromegaly within the intake period. Included patients were aged $\geq 20$ years, had $\geq 3$ months continuous pre-index health care plan eligibility before the diagnosis date, had $\geq 12$ months post-index continuous health care plan eligibility, and fulfilled $\geq 1$ of the following conditions during the intake period: $\geq 2$ independent diagnostic codes for acromegaly (International Classification of Diseases, Ninth Revision, Clinical Modification [ICD-9-CM] code 253.0x); $\geq 1$ acromegaly diagnostic code and $\geq 1$ acromegaly-related procedure code (Appendix A, available in online article); $\geq 1$ acromegaly diagnostic code and $\geq 1$ medical claim for an acromegaly-related therapy (bromocriptine, cabergoline, lanreotide, octreotide, pasireotide, or pegvisomant; Appendix B, available in online article)

\section{Outcomes Measured and Analyses}

The prevalence and incidence of acromegaly during the intake period (March 31, 2008-July 31, 2012) were determined. Prevalence was calculated from the number of acromegaly cases (defined as those who met the criteria described above for acromegaly diagnostic codes and/or acromegaly-related medical claim or procedure codes) divided by the number of individuals in the HIRD who were aged $\geq 20$ years. Incidence rates were calculated from the number of new acromegaly cases (defined as those who had not been diagnosed with acromegaly in the previous $\geq 3$ months to 1 year) within a selected year divided by the number of individuals in the HIRD in that year who were aged $\geq 20$ years. During the study period (January 1 , 2008-July 31, 2013), data regarding comorbidities, treatment patterns, resource utilization, and costs were examined using medical and pharmacy claims from the HIRD to allow for $\geq 3$-month pre-index and $\geq 12$-month post-index observational periods relative to acromegaly diagnosis.

\section{Comorbidities}

During the observation period, acromegaly-related comorbidities (e.g., hypothyroidism, hypertension, and diabetes; Appendix C, available in online article) were evaluated and used to calculate a Deyo-Charlson Comorbidity Index score (Appendix D, available in online article). ${ }^{29,30}$

\section{Treatment Patterns}

Treated patients were defined as those who had $\geq 1$ prescription for octreotide, lanreotide, cabergoline, bromocriptine, 


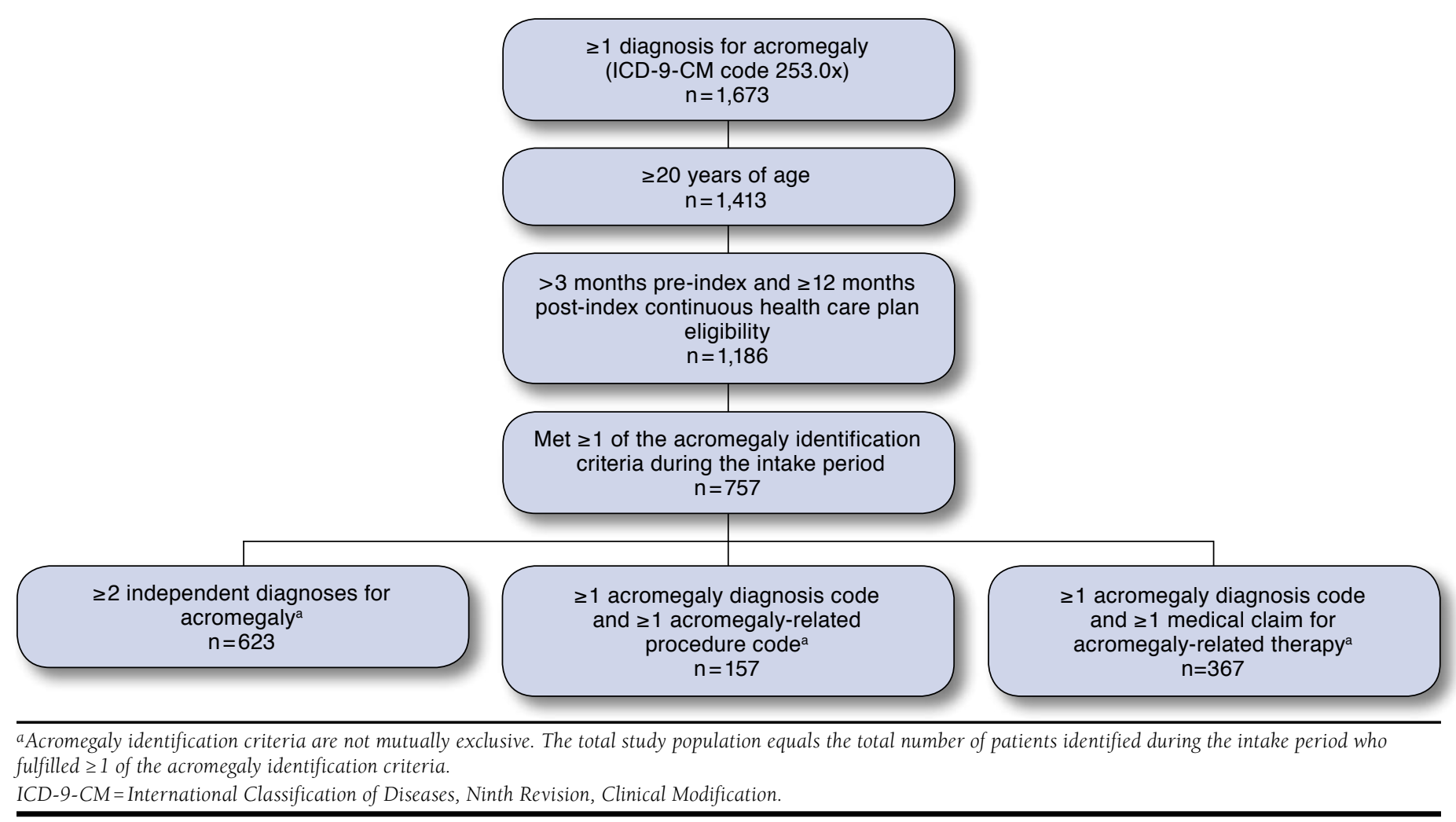

pasireotide, or pegvisomant; had undergone transsphenoidal surgery; or had received radiation therapy during the 1-year post-index observational period. The proportion of treated patients was reported separately for each drug, as were treatment duration, dosing frequency, treatment adherence, treatment persistence, and concomitant medication. Dosing frequency was defined as the number of days between 2 consecutive prescriptions.

Treatment duration was defined as the use of a particular drug without discontinuation (specified as a $\geq 60$-day interruption) and was measured from the index date or the date of first treatment use (whichever occurred later) until discontinuation or the end of the 1-year post-index period (whichever occurred first). Treatment duration was not calculated for patients with a gap in treatment of $\geq 60$ days.

Treatment adherence was defined as the proportion of days covered $(\mathrm{PDC})>80 \% .{ }^{31}$ The PDC was calculated as the number of days covered with the drug during the observational period divided by the number of days in the study period (defined as the index date or the date of the first prescription for the particular drug, whichever occurred later, until the end of the 1 -year study period). Patients with a gap in treatment of $\geq 60$ days were excluded from the PDC calculation. Treatment persistence was defined as the percentage of patients remaining on therapy for the minimum recommended time with no gap in therapy greater than 1.5 times a 1-day supply (bromocriptine, cabergoline, octreotide, pasireotide, and pegvisomant) or greater than 90 days (lanreotide; Appendix B).

Concomitant treatment use required 2 drugs (from among octreotide, lanreotide, cabergoline, bromocriptine, and pegvisomant) to be taken in combination for $\geq 28$ consecutive days. The proportion of patients who received transsphenoidal surgery, radiation therapy, or other procedures frequently associated with acromegaly was also reported.

\section{Health Care Resource Utilization}

An analysis of health care resource utilization was conducted for the study population during the 12-month post-index observational period. Total and acromegaly-related (defined as medical and pharmacy claims associated with diagnosis for acromegaly) health care resource utilization was described for the following services: inpatient hospitalization stays, emergency room (ER) visits, physician office visits, other outpatient services, and prescription drugs. Utilization patterns were also described for patients with $\geq 1$ claim for the corresponding 


\begin{tabular}{|c|c|c|}
\hline & Acromegaly & atients, $\mathrm{N}=757$ \\
\hline \multicolumn{3}{|c|}{ Age group on index date, $\mathrm{n}(\%)$} \\
\hline $20-34$ & 108 & $(14.3)$ \\
\hline $35-44$ & 167 & $(22.1)$ \\
\hline $45-54$ & 215 & $(28.4)$ \\
\hline $55-64$ & 181 & $(23.9)$ \\
\hline $65+$ & 86 & $(11.4)$ \\
\hline \multicolumn{3}{|l|}{ Age, years } \\
\hline Mean (SD) & 49.3 & $(13.9)$ \\
\hline Median (range) & 49 & $(20-93)$ \\
\hline \multicolumn{3}{|l|}{ Gender, n (\%) } \\
\hline Male & 351 & $(46.4)$ \\
\hline Female & 406 & $(53.6)$ \\
\hline \multicolumn{3}{|c|}{ Geographic region on index date, $n(\%)$} \\
\hline Northeast & 156 & $(20.6)$ \\
\hline Midwest & 213 & $(28.1)$ \\
\hline South & 138 & $(18.2)$ \\
\hline West & 227 & $(30.0)$ \\
\hline Unavailable & 23 & $(3.0)$ \\
\hline \multicolumn{3}{|c|}{ Insurance plan type on index date, $\mathrm{n}(\%)$} \\
\hline $\mathrm{HMO}$ & 134 & $(17.7)$ \\
\hline POS & 538 & $(71.1)$ \\
\hline $\mathrm{PPO}$ & 85 & $(11.2)$ \\
\hline \multicolumn{3}{|c|}{ Year of index date, $\mathbf{n}(\%)$} \\
\hline 2008 & 303 & $(40.0)$ \\
\hline 2009 & 162 & $(21.4)$ \\
\hline 2010 & 141 & $(18.6)$ \\
\hline 2011 & 99 & $(13.1)$ \\
\hline 2012 & 52 & $(6.9)$ \\
\hline
\end{tabular}

medical service category and were assessed by place of service (inpatient hospitalizations, ER visits, physician office visits, and other outpatient services). Drug utilization rates were determined for all prescription drugs. In order to assess health care resource utilization, the number of patients with $\geq 1$ claim and the number of claims per person (mean, standard deviation [SD], and median) were calculated.

\section{Costs}

Mean annual health care costs, adjusted to 2012 U.S. dollars using Consumer Price Index medical costs, were estimated during the 12-month post-index observational period. Inflation-adjusted ratios were applied to health care costs before analysis. Both plan-paid and patient-paid costs were examined, with cost components including inpatient hospitalizations, ER visits, physician office visits, other outpatient services, prescription costs, total direct costs (medical costs plus prescription drug costs), and out-of-pocket (patientpaid) costs.

\section{TABLE 2 Comorbidity Characteristics of} Acromegaly Patients $(\mathrm{N}=757)$

\begin{tabular}{|c|c|c|}
\hline & $\begin{array}{l}\text { 3-Month Pre-index } \\
\text { Observation Period }\end{array}$ & $\begin{array}{l}\text { 12-Month Post-index } \\
\text { Observation Period }\end{array}$ \\
\hline \multicolumn{3}{|c|}{ Deyo-Charlson Comorbidity Index } \\
\hline Mean (SD) & $0.58(1.21)$ & $1.15(1.74)$ \\
\hline Median (range) & $0(0-9)$ & $0(0-12)$ \\
\hline \multicolumn{3}{|c|}{ Top 10 acromegaly-related comorbidities, $\mathbf{n}(\%)$} \\
\hline Hypertension & $161(21.3)$ & $338(44.6)$ \\
\hline $\begin{array}{l}\text { Diabetes (including impaired } \\
\text { glucose tolerance) }\end{array}$ & $116(15.3)$ & $215(28.4)$ \\
\hline Hypothyroidism & $104(13.7)$ & $236(31.2)$ \\
\hline $\begin{array}{l}\text { Arthropathy/arthralgia/ } \\
\text { synovitis }\end{array}$ & $90(11.9)$ & $204(26.9)$ \\
\hline $\begin{array}{l}\text { Sleep apnea (obstructive and } \\
\text { central) }\end{array}$ & $58(7.7)$ & $126(16.6)$ \\
\hline Osteoarthritis & $44(5.8)$ & $123(16.2)$ \\
\hline $\begin{array}{l}\text { Solid tumor without } \\
\text { metastasis }\end{array}$ & $43(5.7)$ & $121(16.0)$ \\
\hline Deficiency anemias & $48(6.3)$ & $85(11.2)$ \\
\hline Psychoses $^{\mathrm{a}}$ & $37(4.9)$ & NR \\
\hline Depression & $40(5.3)$ & $90(11.9)$ \\
\hline $\begin{array}{l}\text { Chronic obstructive } \\
\text { pulmonary disease } \\
\end{array}$ & NR & $87(11.5)$ \\
\hline \multicolumn{3}{|c|}{$\begin{array}{l}\text { aIdentified as a top } 10 \text { condition during the pre-index observation period but not } \\
\text { the post-index observation period. } \\
\text { bIdentified as a top } 10 \text { condition during the post-index observation period but not } \\
\text { the pre-index observation period. } \\
N R=\text { not recorded; SD = standard deviation. }\end{array}$} \\
\hline
\end{tabular}

\section{Results}

\section{Patient Characteristics}

A total of 757 patients met the selection criteria for this study (Figure 1), 53.6\% of whom were female $(n=406)$. The mean age of the study population was 49.3 years, with the majority of patients aged 35-64 years on the index date ( $n=563 ; 74.4 \%)$. The most common insurance type in this study population was POS plan ( $n=538 ; 71.1 \%$; Table 1).

\section{Prevalence and Incidence}

The total prevalence of acromegaly between March 31, 2008, and July 31, 2012, was 41.7 cases per million (757 cases out of $18,112,675$ members of the HIRD). Of the 757 new cases identified during this time period, 162 (21.4\%) were identified in 2009, with an incidence of 15.0 new cases per million. Acromegaly incidence decreased each year thereafter, with 13.3 and 9.5 new cases per million in 2010 and 2011, respectively. Incidence rates for 2008 and 2012 are not reported because those estimated in the first year of reporting (2008) may overrepresent new cases for that year, since all patients meeting acromegaly diagnosis criteria were classified as "new-onset" cases, while the 2012 incidence estimate does not represent a full year of data. 
TABLE 3 Medication Use and Treatment Pattern Among Acromegaly Patients ( $N=757$ )

\begin{tabular}{|c|c|c|c|c|c|c|}
\hline & Octreotide & Lanreotide & Cabergoline & Bromocriptine & Pasireotide ${ }^{\mathrm{a}}$ & Pegvisomant \\
\hline \multicolumn{7}{|l|}{ Medication use, n (\%) } \\
\hline Number of patients using therapy during intake period ${ }^{b}$ & $92(12.2)$ & $37 \quad(4.9)$ & $94(12.4)$ & $30 \quad(4.0)$ & $51 \quad(6.7)$ & $29 \quad(3.8)$ \\
\hline $\begin{array}{l}\text { Number of patients using therapy during intake period } \\
\text { with days supply information available, } \mathrm{n} / \mathrm{N}(\%)^{\mathrm{c}}\end{array}$ & $67 / 92(72.8)$ & $31 / 37(83.8)$ & 88/94 (93.6) & $30 / 30(100.0)$ & $0 / 51 \quad(0.0)$ & $29 / 29(100.0)$ \\
\hline \multicolumn{7}{|l|}{ Treatment pattern } \\
\hline Treatment duration, mean (SD), days & $363 \quad(6.3)$ & $363 \quad(6.0)$ & $360(12.0)$ & $358(14.0)$ & NA & $364 \quad(1.9)$ \\
\hline Dosing frequency, mean (SD), days & $7.4 \quad(7.8)$ & $3.8 \quad(3.2)$ & $7.6 \quad(7.4)$ & $8.5 \quad(8.8)$ & NA & $6.7 \quad(8.3)$ \\
\hline PDC, mean (SD) & $72(21.4)$ & $58(23.8)$ & $62(26.2)$ & $74(22.6)$ & NA & $66(29.5)$ \\
\hline $\mathrm{PDC} \geq 80 \%, \mathrm{n}(\%)^{\mathrm{d}}$ & $22(32.8)$ & $7(22.6)$ & $16(18.2)$ & $7(23.3)$ & NA & $11(37.9)$ \\
\hline Using concomitant medications, $\mathrm{n}(\%)^{\mathrm{d}}$ & $11(16.4)$ & $6(19.4)$ & $10(11.4)$ & $1 \quad(3.3)$ & NA & $8(27.6)$ \\
\hline Persistence, $\mathrm{n}(\%) \mathrm{d}$ & $24(35.8)$ & $19(61.3)$ & $24(27.3)$ & $7(23.3)$ & NA & $16(55.2)$ \\
\hline \multicolumn{7}{|c|}{$\begin{array}{l}\text { aUsage of pasireotide in this study was expected to be low because pasireotide was not first approved until December 14, 2012. No pharmacy claims for pasireotide were } \\
\text { reported; individuals identified as using pasireotide were those with a Healthcare Common Procedure Coding System code of J3490 (unclassified drugs). Therefore, no days } \\
\text { supply information was available to calculate dose frequency/duration values. } \\
{ }^{\circ} \text { Calculated as a percentage of the total population ( } n=757 \text { ). } \\
\text { cCalculated as a percentage of patients using that therapy during intake period. } \\
{ }^{d} \text { Calculated as a percentage of patients using that therapy during intake period with days supply information available. } \\
\text { NA=not applicable; PDC= proportion of days covered; SD=standard deviation. }\end{array}$} \\
\hline
\end{tabular}

\section{Comorbidities}

The mean Deyo-Charlson Comorbidity Index was 1.15 during the 12-month post-index period (Table 2). The top 5 acromegaly-related comorbidities during the pre- and post-index observational periods were hypertension, diabetes (including impaired glucose tolerance), hypothyroidism, arthropathy/ arthralgia/synovitis, and sleep apnea (obstructive and central).

\section{Therapy}

Overall, $50.9 \%$ of patients $(n=385)$ used pharmacologic therapy, with cabergoline and octreotide being the most common ( $\mathrm{n}=94 ; 12.4 \%$ and $\mathrm{n}=92 ; 12.2 \%$, respectively; Table 3). For the assessed acromegaly-related pharmacologic therapies, the mean treatment duration ranged from 358 days (bromocriptine) to 364 days (pegvisomant; Table 3). The PDC ranged from $58 \%$ (lanreotide) to $74 \%$ (bromocriptine), with the percentage of patients with $\mathrm{PDC} \geq 80 \%$ ranging from $18.2 \%$ (cabergoline) to $37.9 \%$ (pegvisomant). The highest therapy persistence was observed with lanreotide, where $61.3 \%$ of patients remained on the drug for the recommended amount of time (Table 3, Appendix B).

Transsphenoidal surgery was performed in 121 patients (16.0\%). The most common acromegaly-associated procedure was hypophysectomy or excision of pituitary tumor, which was performed in $8.1 \%$ of patients $(n=61)$. Intracranial neuroendoscopy, radiation therapy, and stereotactic radiation treatment were performed in 6.5\% ( $n=49), 3.8 \%(n=29)$, and $1.6 \%(n=12)$ of patients, respectively. Over half of the patients undergoing surgery $(52.9 \% ; n=64)$ subsequently required $\geq 1$ acromegaly-related medication, indicating that surgery was not curative in these patients. The most common therapies used following surgery were lanreotide $(15.7 \% ; n=19)$, octreotide $(13.2 \% ; n=16)$, and cabergoline $(10.7 \% ; n=13)$. The average time between surgery and initiation of pharmacologic treatment was 34 days (median 0 days; range 0-349 days).

\section{Health Care Resource Utilization}

Acromegaly-related health care utilization is summarized in Table 4. Overall, $18.8 \%$ of patients $(n=142)$ required an acromegaly-related inpatient stay, for a mean duration of 4.7 days (median 3.0 days). Ninety-seven percent of patients $(n=734)$ used outpatient services other than ER or physician visits; $74.8 \%(n=566)$ had a physician office visit; and $1.8 \%$ of patients $(n=14)$ visited the ER for acromegaly-related reasons (Table 4). In the 12-month post-index observational period, $37.0 \%$ of patients $(n=280)$ filed claims for acromegaly-related prescription drugs, and the mean number of acromegalyrelated prescriptions among patients with $\geq 1$ acromegalyrelated prescription claim was 7.6.

For all-cause health care resource utilization (Table 4), $32.9 \%$ of patients $(n=249)$ required an inpatient stay, with a mean and median duration of 6.4 and 3.0 days, respectively. Most patients (99.2\%; $\mathrm{n}=751)$ made physician office visits, and all patients used other outpatient services. In the 12-month post-index observational period, $93.0 \%$ of patients $(n=704)$ filed a prescription claim, with a mean number of 34.5 prescriptions among patients with $\geq 1$ prescription claim.

\section{Costs}

Mean total acromegaly-related medical costs were $\$ 4,757$ (median \$531; SD \$13,176), which, when combined with acromegaly-related pharmacy costs, rose to $\$ 10,903$ (median 


\section{TABLE 4 Health Care Resource Utilization During the 12-Month Post-index Observation Period ( $\mathrm{N}=757$ )}

\begin{tabular}{l|rr|rr}
\hline & $\begin{array}{c}\text { Acromegaly } \\
\text { Related }\end{array}$ & All Cause \\
\hline Inpatient admissions & 142 & $(18.8)$ & 249 & $(32.9)$ \\
\hline Patients with any admission, n (\%) & 0.2 & $(0.5)$ & 0.5 & $(1.4)$ \\
\hline $\begin{array}{l}\text { Number of admissions (all patients), } \\
\text { mean (SD) }\end{array}$ & 1.2 & $(0.4)$ & 1.6 & $(2.0)$ \\
\hline $\begin{array}{l}\text { Number of admissions (among patients } \\
\text { with } \geq 1 \text { admission), mean (SD) }\end{array}$ & 4.7 & $(7.2)$ & 6.4 & $(14.0)$ \\
\hline $\begin{array}{l}\text { Length of stay (among patients with } \geq 1 \\
\text { admission), mean (SD), days }\end{array}$ & & & & \\
\hline
\end{tabular}

Emergency room visits

\begin{tabular}{|c|c|c|}
\hline Patients with any visit, $\mathrm{n}(\%)$ & $14 \quad(1.8)$ & $153(20.2)$ \\
\hline Number of visits (all patients), mean (SD) & $0.0 \quad(0.4)$ & $(0.9)$ \\
\hline $\begin{array}{l}\text { Number of visits (among patients with } \\
\geq 1 \text { visit), mean (SD) }\end{array}$ & $1.6 \quad(2.1)$ & $(1.0)$ \\
\hline \multicolumn{3}{|l|}{ Physician office visits } \\
\hline Patients with any visit, $\mathrm{n}(\%)$ & $566(74.8)$ & $751 \quad(99.2)$ \\
\hline Number of visits (all patients), mean (SD) & $2.4 \quad(2.9)$ & $12.8(11.5)$ \\
\hline $\begin{array}{l}\text { Number of visits (among patients with } \\
\geq 1 \text { visit), mean (SD) }\end{array}$ & $(3.0)$ & $12.9(11.5)$ \\
\hline \multicolumn{3}{|l|}{ Other outpatient services } \\
\hline Patients with any service, $\mathrm{n}(\%)$ & $734(97.0)$ & $757(100)$ \\
\hline Number of services (all patients), mean (SD) & $2.7 \quad(4.0)$ & $16.9(21.7)$ \\
\hline $\begin{array}{l}\text { Number of services (among patients with } \\
\geq 1 \text { service), mean (SD) }\end{array}$ & $2.8 \quad(4.1)$ & $19.6(21.7)$ \\
\hline \multicolumn{3}{|l|}{ Prescription drugs } \\
\hline Patients with any prescription claim, n (\%) & $280(37.0)$ & $704(92.9)$ \\
\hline $\begin{array}{l}\text { Number of prescriptions (all patients), } \\
\text { mean (SD) }\end{array}$ & $2.8 \quad(5.3)$ & $32.1(32.6)$ \\
\hline $\begin{array}{l}\text { Number of prescriptions (among patients } \\
\text { with } \geq 1 \text { acromegaly-related prescription } \\
\text { claim), mean (SD) }\end{array}$ & $7.6 \quad(6.3)$ & $34.5(32.5)$ \\
\hline
\end{tabular}

$\$ 1,012$; SD $\$ 20,646)$. Of these, mean total patient-paid acromegaly-related costs per patient were $\$ 365$ (median $\$ 75$; SD $\$ 869$ ) and $\$ 326$ (median \$0; SD \$1,272) for medical and pharmacy costs, respectively (Table 5). The most expensive acromegaly-related costs were inpatient admissions $(\$ 6,754$; median $\$ 0 ;$ SD $\$ 39,536)$ and prescription drugs $(\$ 6,147$; median \$0; SD \$15,514).

Mean total all-cause medical and pharmacy costs were $\$ 25,021$ (median $\$ 9,154$; SD $\$ 58,559$ ) and $\$ 7,787$ (median $\$ 2,118$; SD $\$ 14,640$ ), respectively (total costs $\$ 32,807$; median $\$ 16,323$; SD $\$ 60,900$ ). Of these costs, each patient paid $\$ 2,001$ (median \$1,169; SD \$2,383) in medical costs and $\$ 876$ (median \$442; SD \$1,456) in pharmacy costs. Like acromegaly-related costs, the most expensive all-cause costs resulted from inpatient admissions, with a mean of $\$ 12,950$ (median $\$ 0$; SD \$58,983).

Unsurprisingly, acromegaly-related and all-cause costs in subsets of patients with $\geq 1$ claim were higher than in the total patient population (data not shown).

\section{Discussion}

Acromegaly is a chronic disease caused by excessive GH secretion, most often from a pituitary adenoma. A majority of diagnosed patients require lifelong medication to control the condition and its associated comorbidities. ${ }^{1-3}$ This study investigated the clinical and economic burden of acromegaly from a U.S health care perspective using claims information from the largest database of commercially insured patients in the United States.

The total prevalence of acromegaly was estimated to be 41.7 cases per million between March 31, 2008, and July 31,2012 . This finding is consistent with previously reported prevalence estimates in European countries of 40-70 cases per million $^{12-14,16-19}$ as well as with a recent U.S. study of 3 medical claims databases, with estimated prevalence rates of 45-64 cases per million between 2011 and 2012. ${ }^{15}$

The estimated annual incidence of acromegaly in this study ranged from 9.5 to 15.0 cases per million. Because of the design of the study, the 2008 and 2012 data did not reflect true 12 -month periods and were excluded from analysis. The incidence estimates for 2009, 2010, and 2011 (15.0, 13.3, and 9.5 new cases per million, respectively) were considerably higher than previous reports of 2-4 million new cases per year and may reflect increased awareness of the disease among physicians and improved diagnostic tools. ${ }^{12-14,16,18,19}$

Consistent with previous studies, ${ }^{14,21,22}$ patients with acromegaly in this study averaged 48.9 years of age at index date, with the largest proportion of patients (28.4\%) falling between the ages of 45 and 54 years. ${ }^{11,15,22}$ Late diagnosis of acromegaly likely stems from the fact that the disease does not always manifest with clear diagnostic features, and it may also be due to the slow-growing nature of pituitary somatotroph adenomas. ${ }^{10,14}$ The proportion of women in this study population (53.6\%) was consistent with previous reports, in which 43\%$61 \%$ of patients with acromegaly were female. ${ }^{12-19}$

As in previous studies, the most common comorbidities observed in this study were hypertension, hypothyroidism, diabetes, arthropathy, and sleep apnea. ${ }^{5,18,32-35}$ Potentially related to these comorbidities, almost one fifth of patients (18.8\%) were hospitalized for acromegaly-related reasons during the study period, with the duration of hospital stay averaging 4.7 days. In support of this observation, a recent study conducted in the United States found that musculoskeletal abnormalities, cardiovascular abnormalities, and sleep apnea in patients with acromegaly significantly increased their odds of hospitalization. ${ }^{33}$

Acromegaly treatment guidelines recommend the use of pharmacotherapy as adjuvant therapy in cases of persistent disease following surgery or as primary therapy in cases for which surgery is not feasible. ${ }^{5}$ In the present study, over half of the patients received acromegaly-specific pharmacotherapy. 
TABLE 5 Health Care Costs per Patient During the 12-Month Post-index Observation Period (N=757)

\begin{tabular}{|c|c|c|c|c|c|c|}
\hline \multirow[b]{3}{*}{ Inpatient admissions } & \multicolumn{3}{|c|}{ Acromegaly-Related Costs (\$) } & \multicolumn{3}{|c|}{ All-Cause Costs (\$) } \\
\hline & \multicolumn{2}{|c|}{ Mean (SD) } & \multirow{2}{*}{$\begin{array}{c}\text { Median } \\
0\end{array}$} & \multicolumn{2}{|c|}{ Mean (SD) } & \multirow{2}{*}{$\begin{array}{r}\text { Median } \\
0\end{array}$} \\
\hline & 6,754 & $(39,536)$ & & 12,950 & $(58,983)$ & \\
\hline Emergency room visits & 32 & $(275)$ & 0 & 410 & $(1,480)$ & 0 \\
\hline Physician office visits & 615 & $(2,884)$ & 179 & 2,228 & $(5,000)$ & 1,259 \\
\hline Other outpatient services & 2,377 & $(10,262)$ & 179 & 9,740 & $(19,229)$ & 3,863 \\
\hline Prescription drugs & 6,147 & $(15,514)$ & 0 & 7,787 & $(14,640)$ & 2,118 \\
\hline \multicolumn{7}{|l|}{ Total costs } \\
\hline Medical costs & 4,757 & $(13,176)$ & 531 & 25,021 & $(58,559)$ & 9,154 \\
\hline Medical + pharmacy costs ${ }^{\mathrm{a}}$ & 10,903 & $(20,646)$ & 1,012 & 32,807 & $(60,900)$ & 16,323 \\
\hline \multicolumn{7}{|c|}{ Total patient-paid costs, per patient } \\
\hline Medical costs & 365 & $(869)$ & 75 & 2,001 & $(2,383)$ & 1,169 \\
\hline Pharmacy costs & 326 & $(1,272)$ & 0 & 876 & $(1,456)$ & 442 \\
\hline Medical + pharmacy costs ${ }^{\mathrm{a}}$ & 691 & $(1,551)$ & 136 & 2,876 & $(2,912)$ & 2,020 \\
\hline
\end{tabular}

Among these, cabergoline and octreotide were the most common medications prescribed. However, adherence rates (PDC $\geq 80 \%$ ) to pharmacologic treatment were generally low, with $18.2 \%$ and $32.8 \%$ adherence associated with cabergoline and octreotide, respectively. Persistence rates were also surprisingly low, with the highest persistence observed for lanreotide treatment (61.3\%). Previous research has suggested that low adherence to acromegaly treatment may be due to patients' discontinuing treatment when their symptoms either appear to resolve or are mild and do not improve with therapy, ${ }^{36}$ a phenomenon commonly observed in other chronic diseases. ${ }^{37,38}$ These adherence rates may also have been affected by a number of factors, including drug administration route (oral, intravenous, or subcutaneous); complexity of administration (e.g., dosing frequency); and tolerability. For instance, octreotide, lanreotide, pasireotide, and pegvisomant are each administered parenterally, with dosing frequency that varies from 4 times per day to once every 4 weeks (Appendix B). In contrast, bromocriptine and cabergoline are oral medications that are most commonly dosed once daily or twice weekly, respectively (Appendix B).

In this study, mean total acromegaly-related and all-cause costs (including medical and pharmacy costs) were $\$ 10,903$ and $\$ 32,807$, respectively; these costs were driven primarily by inpatient admissions and prescription drugs. While published studies describing the economic burden of acromegaly are limited, these results are consistent with previous studies demonstrating that medications are one of the largest contributors to cost and that complications and/or comorbidities are associated with increased costs compared with acromegaly alone. ${ }^{23-28}$ In particular, a recent U.S. study of patients with acromegaly found mean health care costs (reported in 2009 U.S. dollars) to be $\$ 24,900$ per patient-year, driven largely by pharmacy costs $(\$ 7,185 ; 28.5 \%)$ and inpatient hospitalization costs $(\$ 5,213 ; 20.9 \%) .{ }^{23}$

\section{Limitations}

A key limitation in the design of this study was that included patients were only required to have a minimum of 3 months of continuous pre-index health care plan eligibility before the diagnosis date. While $a \geq 12$-month pre-index period would have been preferable, the resulting sample size would have been too small for analysis. This study was also limited because the index date represented the first acromegaly diagnosis in each patient. If patients received therapy in the pre-index period but not in the post-index period, use in the pre-index period would likely not have been captured in the study results. Therefore, these results could have underestimated treatment utilization for these patients. A further limitation concerns the 2008 and 2012 estimates for acromegaly incidence. In 2008, all patients meeting acromegaly diagnosis criteria were classed as "new-onset" cases at the beginning of the intake period, whereas in 2012, only the first 7 months of the year were assessed. Therefore, the 2008 and 2012 figures do not accurately represent incidence in the general population and were excluded from analysis.

\section{Conclusions}

The results presented in this study confirm that acromegaly is a rare condition associated with multiple comorbidities. Hospitalizations and pharmacotherapy were the largest drivers of acromegaly-related costs, possibly because of severe comorbidities. Improved disease management may reduce the clinical and economic burden experienced by patients with acromegaly. 


\section{Authors}

HILARY PLACZEK, PhD, MPH, is Associate Director, Population Health Analytics, GNS Healthcare, Cambridge, Massachusetts. YAPING XU, MD, MPH, is Principal Health Economist; YUNMING MU, PhD, is Senior Statistical Scientist; and SUSAN M. BEGELMAN, MD, is Group Medical Director, US Medical Affairs, Genentech, South San Francisco, California. MAXINE FISHER, $\mathrm{PhD}$, is Director, Real World Evidence, Vector Oncology, Memphis, Tennessee.

AUTHOR CORRESPONDENCE: Hilary Placzek, PhD, MPH, GNS Healthcare, One Charles Park, Cambridge, MA 02142-1254. Tel.: 617.600.8667; E-mail: hplaczek@gmail.com.

\section{DISCLOSURES}

This work was supported by Genentech, which also provided funding for medical writing and editorial support for the development of this manuscript. At the time of this analysis, Placzek and Fisher were employees of HealthCore, which received funding from Genentech to perform the analysis. Begelman, $\mathrm{Mu}$, and $\mathrm{Xu}$ are employees of Genentech, a member of the Roche Group, and own Roche stock or stock options.

All authors contributed to the study concept. Placzek, Fisher, and Xu contributed to study design. Placzek and Fisher contributed to data collection. All authors contributed to data interpretation and writing and revision of the manuscript.

\section{ACKNOWLEDGMENTS}

Ryan Woodrow, BSc, and Morgan C. Hill, PhD, on behalf of Infusion Communications, provided writing support based on input from authors, and Joshua Safran of Infusion Communications copyedited and styled the manuscript per journal requirements.

\section{REFERENCES}

1. Manjila S, Wu OC, Khan FR, Khan MM, Arafah BM, Selman WR. Pharmacological management of acromegaly: a current perspective. Neurosurg Focus. 2010;29(4):E14. Available at: http://thejns.org/doi/full/10. 3171/2010.7.FOCUS10168. Accessed November 1, 2015.

2. Melmed S. Acromegaly pathogenesis and treatment. J Clin Invest. 2009;119(11):3189-202. Available at: http://www.jci.org/articles/view/39375. Accessed November 1, 2015.

3. Chanson P, Salenave S, Kamenicky P, Cazabat L, Young J. Pituitary tumours: acromegaly. Best Pract Res Clin Endocrinol Metab. 2009;23(5):555-74.

4. Rajasoorya C, Holdaway IM, Wrightson P, Scott DJ, Ibbertson HK. Determinants of clinical outcome and survival in acromegaly. Clin Endocrinol (Oxf). 1994:4l(1):95-102

5. Katznelson L, Laws ER Jr, Melmed S, et al. Acromegaly: an endocrine society clinical practice guideline. J Clin Endocrinol Metab. 2014;99(11):3933-51.

6. Dekkers OM, Biermasz NR, Pereira AM, Romijn JA, Vandenbroucke JP. Mortality in acromegaly: a meta-analysis. J Clin Endocrinol Metab. 2008;93(1):61-67. Available at: http://press.endocrine.org/doi/full/10.1210/ jc.2007-1191. Accessed November 1, 2015.

7. Holdaway IM, Bolland MJ, Gamble GD. A meta-analysis of the effect of lowering serum levels of GH and IGF-I on mortality in acromegaly. Eur J Endocrinol. 2008;159(2):89-95. Available at: http://www.eje-online.org/content/159/2/89.long. Accessed November 1, 2015.
8. Holdaway IM, Rajasoorya RC, Gamble GD. Factors influencing mortality in acromegaly. J Clin Endocrinol Metab. 2004;89(2):667-74. Available at: http://press.endocrine.org/doi/full/10.1210/jc.2003-031199. Accessed November 1, 2015.

9. Burton T, Le NE, Bancroft T, Neary M. Real-world comorbidities and treatment patterns of patients with acromegaly in two large U.S. health plan databases. Pituitary. 2013;16(3):354-62. Available at: http://www.ncbi.nlm. nih.gov/pmc/articles/PMC3730090/. Accessed November 1, 2015.

10. Adelman DT, Liebert KJ, Nachtigall LB, Lamerson M, Bakker B. Acromegaly: the disease, its impact on patients, and managing the burden of long-term treatment. Int J Gen Med. 2013;6:31-38. Available at: http://www. ncbi.nlm.nih.gov/pmc/articles/PMC3555549/. Accessed November 1, 2015.

11. Reid TJ, Post KD, Bruce JN, Nabi KM, Reyes-Vidal CM, Freda PU. Features at diagnosis of 324 patients with acromegaly did not change from 1981 to 2006: acromegaly remains under-recognized and under-diagnosed Clin Endocrinol (Oxf). 2010;72(2):203-08. Available at: http://www.ncbi.nlm. nih.gov/pmc/articles/PMC2866138/. Accessed November 1, 2015.

12. Alexander L, Appleton D, Hall R, Ross WM, Wilkinson R. Epidemiology of acromegaly in the Newcastle region. Clin Endocrinol (Oxf). 1980;12(1):71-79.

13. Bengtsson BA, Eden S, Ernest I, Oden A, Sjogren B. Epidemiology and long-term survival in acromegaly. A study of 166 cases diagnosed between 1955 and 1984. Acta Med Scand. 1988;223(4):327-35.

14. Bex M, Abs R, T'Sjoen G, et al. AcroBel-the Belgian registry on acromegaly: a survey of the "real-life" outcome in 418 acromegalic subjects. Eur J Endocrinol. 2007;157(4):399-409. Available at: http://www.eje-online.org/ content/157/4/399.long. Accessed November 1, 2015

15. Cantrell RA, Walls R, Singh N, et al. Prevalence and demographic characteristics of acromegaly in the United States. Pharmacoepidemiol Drug Safety. 2014;23(S1):52. [Abstract 95].

16. Etxabe J, Gaztambide S, Latorre P, Vazquez JA. Acromegaly: an epidemiological study. J Endocrinol Invest. 1993;16(3):181-87.

17. Fernandez A, Karavitaki N, Wass JA. Prevalence of pituitary adenomas: a community-based, cross-sectional study in Banbury (Oxfordshire, UK). Clin Endocrinol (Oxf). 2010;72(3):377-82. Available at: http://onlinelibrary. wiley.com/doi/10.1111/j.1365-2265.2009.03667.x/full. Accessed November $1,2015$.

18. Mestrón A, Webb SM, Astorga R, et al. Epidemiology, clinical characteristics, outcome, morbidity and mortality in acromegaly based on the Spanish Acromegaly Registry (Registro Espanol de Acromegalia, REA). Eur J Endocrinol. 2004;151(4):439-46. Available at: http://www.eje-online.org/content/151/4/439.long. Accessed November 1, 2015

19. Ritchie CM, Atkinson AB, Kennedy AL, et al. Ascertainment and natural history of treated acromegaly in Northern Ireland. Ulster Med J. 1990;59(1):55-62. Available at: http://www.ncbi.nlm.nih.gov/pmc/articles/ PMC2448267/pdf/ulstermedj00078-0062.pdf. Accessed November 1, 2015

20. Rosario PW, Calsolari MR. Screening for acromegaly by application of a simple questionnaire evaluating the enlargement of extremities in adult patients seen at primary health care units. Pituitary. 2012;15(2):179-83.

21. Schneider HJ, Sievers C, Saller B, Wittchen HU, Stalla GK. High prevalence of biochemical acromegaly in primary care patients with elevated IGF-1 levels. Clin Endocrinol (Oxf). 2008;69(3):432-35.

22. Ezzat S, Forster MJ, Berchtold P, Redelmeier DA, Boerlin V, Harris AG. Acromegaly. Clinical and biochemical features in 500 patients. Medicine (Baltimore). 1994;73(5):233-40.

23. Broder MS, Neary MP, Chang E, Cherepanov D, Katznelson L. Treatments, complications, and healthcare utilization associated with acromegaly: a study in two large United States databases. Pituitary. 2014;17(4):333-41

24. Didoni G, Grottol S, Gasco V, et al. Cost-of-illness study in acromegalic patients in Italy. J Endocrinol Invest. 2004;27(11):1034-39. 
25. Knutzen R, Ezzat S. The cost of medical care for the acromegalic patient. Neuroendocrinology. 2006;83(3-4):139-44.

26. Luque-Ramirez M, Paramo C, Varela da CC, Garcia-Mayor RV. Cost of management of invasive growth hormone-secreting macroadenoma. J Endocrinol Invest. 2007;30(7):541-45

27. Roset M, Merino-Montero S, Luque-Ramirez M, et al. Cost of clinical management of acromegaly in Spain. Clin Drug Investig. 2012;32(4):235-45.

28. Wilson LS, Shin JL, Ezzat S. Longitudinal assessment of economic burden and clinical outcomes in acromegaly. Endocr Pract. 2001;7(3):170-80.

29. Charlson ME, Pompei P, Ales KL, MacKenzie CR. A new method of classifying prognostic comorbidity in longitudinal studies: development and validation. J Chronic Dis. 1987;40(5):373-83.

30. Deyo RA, Cherkin DC, Ciol MA. Adapting a clinical comorbidity index for use with ICD-9-CM administrative databases. J Clin Epidemiol. 1992;45(6):613-19.

31. Ho PM, Bryson CL, Rumsfeld JS. Medication adherence: its importance in cardiovascular outcomes. Circulation. 2009;119(23):3028-35. Available at: http://circ.ahajournals.org/content/119/23/3028.long. Accessed November $1,2015$.
32. Attal P, Chanson P. Endocrine aspects of obstructive sleep apnea. J Clin Endocrinol Metab. 2010;95(2):483-95. Available at: http://press.endocrine.org/ doi/full/10.1210/jc.2009-1912. Accessed November 1, 2015.

33. Colao A, Pivonello R, Scarpa R, Vallone G, Ruosi C, Lombardi G. The acromegalic arthropathy. J Endocrinol Invest. 2005;28(8 Suppl):24-31.

34. Kasayama S, Otsuki M, Takagi M, et al. Impaired beta-cell function in the presence of reduced insulin sensitivity determines glucose tolerance status in acromegalic patients. Clin Endocrinol (Oxf). 2000;52(5):549-55.

35. Lacks S, Jacobs RP. Acromegalic arthropathy: a reversible rheumatic disease. J Rheumatol. 1986;13(3):634-36.

36. Kasuki L, Marques NV, Nuez MJ, Leal VL, Chinen RN, Gadelha MR. Acromegalic patients lost to follow-up: a pilot study. Pituitary. 2013;16(2): 245-50.

37. Cohen BA. Adherence to disease-modifying therapy for multiple sclerosis. Int J MS Care. 2006;8(S1):32-37. Available at: http://ijmsc.org/doi/ pdf/10.7224/1537-2073-8.S1.4. Accessed November 1, 2015.

38. Neutel JM, Smith DH. Improving patient compliance: a major goal in the management of hypertension. J Clin Hypertens (Greenwich). 2003;5(2):127-32. Available at: http://onlinelibrary.wiley.com/doi/10.1111/j.15246175.2003.00495.x/full. Accessed November 1, 2015. 


\section{APPENDIX A Acromegaly-Related CPT and ICD-9-CM Procedure Codes}

\begin{tabular}{|c|c|c|}
\hline \multirow[b]{2}{*}{ Description } & \multicolumn{2}{|c|}{ Procedure Code } \\
\hline & CPT & ICD-9-CM \\
\hline Craniotomy for hypophysectomy or excision of pituitary tumor, intracranial approach & 61546 & \\
\hline Hypophysectomy or excision of pituitary tumor, transnasal or transseptal approach, nonstereotactic & 61548 & \\
\hline Neuroendoscopy, intracranial; with excision of pituitary tumor, transnasal or transsphenoidal approach & 62165 & \\
\hline $\begin{array}{l}\text { Radiation treatment delivery, stereotactic radiosurgery, complete treatment course of cranial lesion(s) consisting of } \\
1 \text { session; multisource Cobalt } 60 \text { based }\end{array}$ & 77371 & \\
\hline $\begin{array}{l}\text { Radiation treatment delivery, stereotactic radiosurgery, complete treatment course of cranial lesion(s) consisting of } \\
1 \text { session; linear accelerator based }\end{array}$ & 77372 & \\
\hline Stereotactic radiation treatment management of cranial lesion(s) (complete course of treatment consisting of 1 session) & 77432 & \\
\hline Partial excision of pituitary gland, transfrontal approach & & 07.61 \\
\hline Partial excision of pituitary gland, transsphenoidal approach & & 07.62 \\
\hline Partial excision of pituitary gland, unspecified approach & & 07.63 \\
\hline Total excision of pituitary gland, transfrontal approach & & 07.64 \\
\hline Total excision of pituitary gland, transsphenoidal approach & & 07.65 \\
\hline Total excision of pituitary gland, other specified approach & & 07.68 \\
\hline Total excision of pituitary gland, unspecified approach & & 07.69 \\
\hline Stereotactic radiosurgery, not otherwise specified & & 92.30 \\
\hline Stereotactic radiosurgery, not elsewhere classified & & 92.39 \\
\hline
\end{tabular}


APPENDIX B List of Acromegaly-Related Medications, Dosing Recommendations, and Persistence Definition

\begin{tabular}{|c|c|c|c|c|c|}
\hline $\begin{array}{l}\text { Acromegaly-Related } \\
\text { Drug }\end{array}$ & Category & HCPCS Codes & NDC Numbers & Dosing Frequency & $\begin{array}{c}\text { Persistence } \\
\text { Definition }\end{array}$ \\
\hline Bromocriptine & $\begin{array}{l}\text { Dopamine } \\
\text { agonist }\end{array}$ & & $\begin{array}{l}00078001705,00078001715,00078001765, \\
00078010205,00078010215,00378024201, \\
00378024293,00378204201,00378204293, \\
00378709601,00378709693,00574010601, \\
00574010603,00615453143,00615453153, \\
00615453163,00781181701,00781181731, \\
00781211901,00781211931,00781281901, \\
00781281931,00781532501,00781532531, \\
00832010500,00832010503,00832011200, \\
00832011203,30698001701,30698001730, \\
30698010230,38779019601,38779019603, \\
38779019606,38779019611,38779019615, \\
49452130801,49452130802,51552104002, \\
51927227400,54569040200,54569040300, \\
54868566700,54868566701,54868566702, \\
54977023930,57866902401,58016092120, \\
58016092130,60346013430,66685590500, \\
66685590503,68012025820,68258912201, \\
68258914401,68382011001,68382011006\end{array}$ & 1 per day (oral) & 1.5 days supply \\
\hline Cabergoline & Dopamine agonist & $\mathrm{J} 8515$ & $\begin{array}{l}00013700112,00093542088,16252053608, \\
49884067314,59762010001,60505259702 \\
68084024511,68084024521\end{array}$ & $\begin{array}{l}2 \text { times per week } \\
\text { (oral) }\end{array}$ & 1.5 days supply \\
\hline Lanreotide & $\begin{array}{l}\text { Somatostatin } \\
\text { analog }\end{array}$ & J1930 & $\begin{array}{l}15054006001,15054006001,15054009001, \\
15054009001,15054012001,15054012001, \\
15054012002\end{array}$ & $\begin{array}{l}\text { Injections typically } \\
\text { given once every } 4 \\
\text { weeks for } 3 \text { months }\end{array}$ & 90 days \\
\hline Octreotide & $\begin{array}{l}\text { Somatostatin } \\
\text { analog }\end{array}$ & $\mathrm{J} 2353+\mathrm{J} 2354$ & $\begin{array}{l}\text { 00078018001, } 00078018003,00078018004, \\
00078018015,00078018061,00078018101, \\
00078018103,00078018104,00078018115, \\
00078018161,00078018201,00078018203, \\
00078018204,00078018217,00078018261, \\
00078018325,00078018425,00078034061, \\
00078034061,00078034084,00078034161, \\
00078034161,00078034184,00078034261, \\
00078034261,00078034284,00703330104, \\
00703331101,00703331104,00703332101, \\
00703332104,00703332194,00703333301, \\
00703334301,00781316475,00781316575, \\
00781916475,00781916575,00781916671, \\
00781916695,00781916771,00781916795, \\
00781916871,00781916895,55390016010, \\
55390016110,55390016210,55390016301, \\
55390016401,55390037510,55390037610, \\
55390037701,62756034844,62756034944, \\
62756035040,62756035144,62756035240, \\
62756065240,63323036501,63323037601, \\
63323037701,63323037805,63323037905, \\
64679063201,64679063302,64679063401, \\
64679063502,67457023901,67457024501, \\
67457024601\end{array}$ & $\begin{array}{l}\text { Octreotide immedi- } \\
\text { ate-release injection } \\
\text { is usually injected } 2 \\
\text { to } 4 \text { times a day. } \\
\text { Octreotide long- } \\
\text { acting injection is } \\
\text { usually injected once } \\
\text { every } 4 \text { weeks }\end{array}$ & 1.5 days supply \\
\hline Pasireotide $^{\mathrm{a}}$ & $\begin{array}{l}\text { Somatostatin } \\
\text { analog }\end{array}$ & $\begin{array}{l}\text { C9399/J3490 } \\
\text { (nonspecific } \\
\text { drug codes) }\end{array}$ & $\begin{array}{l}00078063306,00078063320,00078063361, \\
00078063406,00078063420,00078063461, \\
00078063506,00078063520,00078063561\end{array}$ & $\begin{array}{c}\text { Injected } \\
\text { subcutaneously, } \\
\text { usually twice daily }\end{array}$ & 1.5 days supply \\
\hline Pegvisomant & $\begin{array}{c}\text { Growth hormone } \\
\text { antagonist }\end{array}$ & & $\begin{array}{l}00009517502,00009517601,00009517602, \\
00009517801,00009517802,00009518001 \\
00009518002\end{array}$ & $\begin{array}{c}\text { Subcutaneous } \\
\text { injection given daily }\end{array}$ & 1.5 days supply \\
\hline
\end{tabular}

aUsage of pasireotide in this study was expected to be low because pasireotide was not first approved until December 14, 2012.

HCPCS = Healthcare Common Procedure Coding System; NDC= National Drug Code. 


\section{APPENDIX C Acromegaly-Related Comorbidity ICD-9-CM Codes}

Comorbidity

Visual field defects

Hypopituitarism

Osteoarthritis

Arthropathy/arthralgia/synovitis

Kyphosis and scoliosis

Vertebral fracture

Carpal tunnel syndrome

Myopathy/myalgia

Hypertension

Cardiomyopathy

Cardiac hypertrophy

Heart failure

Valvular heart disease

Cardiac dysrhythmia/arrhythmia

Nasal polyps

Sleep apnea (obstructive and central)

Narcolepsy

Diabetes (including impaired glucose tolerance)

Galactorrhea

Menstrual abnormality

Impaired libido/impotence

Colon polyp

Hyperhydrosis

\section{ICD-9-CM Codes}

$368.4 \mathrm{x}$

$253.2,253.7$

$715 . x x$

713.x, 716.4x-716.5x, 716.8x-716.9x, 719.4x, 727.0x

$737.1 \mathrm{x}, 737.3 \mathrm{x}-737.9$

$733.13,805 . x x-806 . x x$

354.0

359.5-359.9, 729.1

362.11, 401.xx-405.xx, 642.0x-642.2x, 642.7x

$425.4,425.7-425.9$

429.3

402.01, 402.11, 402.91, 404.01, 404.03, 404.11, 404.13, 404.91, 404.93, 428.xx

424.xx

427.xx

$471 . x$

$327.20-327.21,327.23,327.26-327.29,780.51,780.53,780.57$

$347 . \mathrm{xx}$

249.xx-250.xx, 357.2, 362.0x, 366.41, 648.0x, 790.2x, 996.57, V45.85, V53.91, V58.67

$611.6,676.6 \mathrm{x}$

$626 . x, 627.0-627.1$

$302.72,607.84,799.81$

211.3

$705.2 \mathrm{x}, 780.8$

ICD-9-CM = International Classification of Diseases, Ninth Revision, Clinical Modification.

\section{APPENDIX D Definition of the Deyo-Charlson Comorbidity Index (DCI) Score29}

\section{DCI algorithm:}

DCI score $=$ sum (Myocardial Infarction + Congestive Heart Failure + Peripheral Vascular Disease + Cardiovascular Disease + Dementia + Chronic Obstructive Pulmonary Disease + Rheumatologic Disease + Peptic Ulcer Disease + max [(Mild Liver Disease) or $(3 \times$ Moderate Liver Disease)] + max [(Mild Diabetes) or $(2 \times$ Chronic Diabetes $)]+[2 \times$ Hemiplegia $]+[2 \times$ Renal Disease $]+\max [(2 \times$ Malignancy $)$ or $(6 \times$ Metastatic Solid Tumor $)]+[6 \times$ AIDS $]$, where the name of each condition represents the number of ICD-9-CM diagnosis codes

\begin{tabular}{|c|c|c|}
\hline Weights & Condition & ICD-9-CM Codes \\
\hline \multirow[t]{10}{*}{1} & Myocardial infarction & $410 . x x, 412$ \\
\hline & Congestive heart failure & $428 . x x$ \\
\hline & Peripheral vascular disease & $441 . x, 443.9,785.4, \mathrm{~V} 43.4,38.48$ \\
\hline & Cerebrovascular disease & $430-437 . x, 438$ \\
\hline & Dementia & $290 . x$ \\
\hline & Chronic obstructive pulmonary disease & $490-496,500-505,506.4$ \\
\hline & Rheumatologic disease & $710.0-710.1,714.0-714.2,714.81,725$ \\
\hline & Peptic ulcer disease & $\begin{array}{l}531.4 x-531.7 x, 532.4 x-532.7 x, 533.4 x-533.7 x, 534.4 x-534.7 x, 531.0 x-531.3 x, 532.0 x-532.3 x \\
533.0 x-533.3 x, 534.0 x-534.3 x, 531.9,532.9,533.9,534.9\end{array}$ \\
\hline & Mild liver disease & $571.2,571.4,571.5,571.6$ \\
\hline & Diabetes, mild to moderate & $250.0 x-250.3 x, 250.7 x$ \\
\hline \multirow[t]{4}{*}{2} & Hemiplegia or paraplegia & $342 . x, 344.1$ \\
\hline & Moderate or severe renal disease & 582.x, 583.0-583.7, 585, 586, 588.x \\
\hline & Diabetes + complications & $250.4 x-250.6$ \\
\hline & Malignancy & 140.x-172.x, 174.x-195.x, 200.xx-208.xx \\
\hline 3 & Moderate-to-severe liver disease & $572.2-572.8,456.0-456.2 x$ \\
\hline \multirow[t]{2}{*}{6} & Metastatic solid tumor & 196.x-199.x \\
\hline & AIDS & 042.x-044.x \\
\hline
\end{tabular}

AIDS = acquired immunodeficiency syndrome; ICD-9-CM=International Classification of Diseases, Ninth Revision, Clinical Modification. 